\title{
ESTUDO SÔBRE O TRATAMENTO DE ALGUMAS INFECÇס̃ES COM LAURILSULFATO DE TETRACICLINA *
}

\author{
Egomar L. Edelweiss **, Sofia M. Martins *** e Antônio R. Milhem ***
}

Os autores tecóm considerações gerais sôbre o uso dos derivalos das tetrociclinas nas infecções.

Descrevem sua experiência com um composto injetávcl, o laurilsulfato ae tetraciclina.

Trataram 19 infecções diversas com êste medicamento: 5 anginas agudas, \& pneumopatias, 2 rnterocol tes agutas, 1 furunculose, 1 pielonefrite, 1 erisipela, e um panarício. Obtiveram 15 resultados excelentes e 1 bom o que eleva a porcentagem de sucessos a $842 \%$.

Não observaram fenómenos secundários imputáveis à droga, salvo manifestações alérgicas em um paciente.

Estamos ainda para conseguir a droga Ideal no tratamento das infecçōes bacterianas. Por mais agentes terapêticos que se descubram, a gama dêstes processos é tão vasta e imprevisível que torna obrigatória a pesquisa de novos medicamentos mais eficazes e menos nocivos.

A descoberta da clortetraciclina em 1948 (4) e, sobretudo, o preparo poster or da tetraciclina por Boothe et al. (2) propiciaram aos investigadores vasto campo de trabalho. Os antibióticos dêste grupo foram, desde então, graças a seu amplo espectro de atividade, experimentados e usados nas mais diversas infecçōes.

A resistência às tetraciclinas é, em geral, gradativa, continuando as bactérias ainda sensíveis a concentraçōes mais altas. Este fato tem dirigido as investigaçōes no sentido de se conseguirem derivados capazes de determinar maiores niveis sanguinea de antibiótico.

Têm sido particularmente estudados, com êste fim, a associação de ácidos policarboxílicos, como o tartárico e o cítrico, aos compostos tetraciclínicos usados por viu oral. Este artefato permite a manutença de taxas mais elevadas de substância ativa no sangue, sem maiores riscos de complicações ou fenômenos colaterais.

Outros autores, como Fabre (5), dedicaram a sua atenção a novos produtos, suft. cientes por si só para obter altas concentraçōes de antibiótico no sôro e nos tecidos.

Os preparados injetáveis, pela sua util dade, constituem um capítulo especial.

Grande número dos derivados solúvets demonstrou vários inconvenientes. Com alguns, como o cloridrato de tetraciclina,

Trabalho realizado na Disciplina de Doenças Infecciosas e Parasitárias da Faculdade Católica Medicina - P. Alegre.

* Professor da Disciplina. Professor adjunto da Cadeira de Doenças Tropicais e Infecciosas da Paeul. dade de Medicina de Pôrto Alegre, U.F.R.G.S.

\#Assistantes da Disciplina. 
ocorre, no local da injeção intramuscular, precipitado que acarreta necrose tecidual.

Em outros, como a pirrolidinometiltetraciclina, a tolerância local é boa, mas a absorção é rápida e os níveis hemáticos baixam ràpidamente, determinando a repetida administração do medicamento.

Em diversos países, vários experimentadores procuraram obter um derivado de tetraciclina, insolúvel em água, de lenta absorção e boa tolerância.

Schoog e Schoog, em 1960, descreveram os resultados obtidos com a ditetraciclina e Belozerova e col., em 1963, relataram seus trabalhos sôbre sais de ácidos graxos de tetraciclina. Ambos os preparados são de pêso molecular elevado e contém radicais lipossolúveis (8).

Izquierdo e col. (8) analisaram oito compostos derivados de tetraciclina dos quais quatro hidrossolúveis e quatro lipossolúveis.

Dentre êstes últimos, sua atenção se fixou especialmente no laurilsulfato de tetraciclina (lauraciclina) em que constataram as seguintes caracteristicas:

1.0 - O laurilsulfato de tetraciclina apresenta, "In vitro" atividade bacteriostática correspondente a seu conteúdo em tetraoiclina.

2:0 - Sua tolerância local é muito boa, bastante superior a de outros compostos estudados.

$3: 0$ - Sua toxidez se sobrepōe à da base: $\therefore 4.9$ - Os niveis sanguíneos obtidos são nittdamente superiores aos observados com a cloridrato de tetraciclina. Mantém concentrações bacteriostáticas durante 18 a 30 horas, atingindo o máximo da curva cêrca de 15 horas após a injeção.

5.0- legítimo pensar que a utilização do laurilsulfato de tetraciclina permitirá obter niveis hemáticos adequados durante um periodo relativamente longo.

6.0 - Parece haver acúmulo não desprezivel da substância ativa nos pulmões e no coração, contràriamente ao que se observa com os derivados hidrossolúveis.

Outras observaçōes de Izquierdo e Goñalons (9) não só confirmaram a excelente tolerância do laurilsulfato de tetraciclina, como atnida tonel íram que a administração reiterada do produto dava lugar a um notável acréscimo das concentrações hemáticas. As injeções repetidas de $250 \mathrm{mg}$ cada oito horas, em coelhos, obtiveram, depois do terceiro dia, concentrações de acima de $24 \mathrm{mcg}$ de tetraciclina por $\mathrm{ml}$ de sangue, isto é, pelo menos quatro vêzes mais do que as alcançadas com outros derivados, usados na mesma dose.

Vinte e quatro horas após a experiência de 5 dias, o lote de 5 coêlhos injetados com 3 doses diárias de $250 \mathrm{mg}$ de laurilsulfato de tetraciclina foi sacrificado. Nenhum dos animais apresentou lesões nem locais, nem à distância. Em apenas dois ocorreu, no lugar da injeção, pequeno depósito amarelo bem tolerado.

Em todos os outros quatro lotes, tratados com diversos derivados de tetraciclina, havia ou zonas hemorrágicas ou necrose da pele e dos músculos.

Estas observações em animais foram plenamente confirmadas por Foz e col. (6) no homem, com injeções de $500 \mathrm{mg}$ de 12 em 12 horas.

Podemos dizer com Alarcos Llorach et al. (1) que o preparado se caracteriza pelos seguintes atributos:

1.0 - Baixa capacidade de lesionar os tecidos.

2.0 - Tolerância de altas doses por via parenteral.

3.0 - Elevados niveis sanguíneos.

4. - Acréscimo progressivo da concentração hemática, com doses reiteradas.

5. - Acúmulo notável da substância ativa em tecidos.

6.0 - Possivel ação bactericida frente a alguns germes.

As observaçōes clínicas se sucederam ao periodo experimental.

As indicações são as mesmas da tetraciclina, levando, porém, em consideração os altos niveis hemáticos atingidos com o laurilsulfato de tetraciclina que ampliam o seu campo de ação.

Foz e col, (6) em 43 doentes com infecções diversas obtiveram 16 resultados excelentes, 12 bons, 10 discretos e 5 nulos.

Alarcos Llorach et al. (1) empregaram o medicamento em doses de $250 \mathrm{mg}$ para adultos e $100 \mathrm{mg}$ para crianças, cada 12 horas nos dois primeiros dias e, posteriormente, de 24 em 24 horas. Seu grupo constava de 118 doentes com as mais variadas infec- 
ções clínicas e cirúrgicas. Conseguiram 111 bons resultados.

Não verificaram fenômenos tóxicos gerais, nem manifestações alérgicas.

González y González e Rubio Clemente, (7) analisaram 11 pacientes com inferção urinária. O agente etiológico foi, em 8 vêzes, a Escherichia coli en 6 das quais era sensivel à lauraciclina. Nestes, obtêm 5 bons resultados. Atribuem 0 insucesso do 6. ${ }^{\circ}$, à litiase concomitante, de que é portador.

Campomanes Gallego e col. (3) estudaram em 31 pacientes a ação e a eliminação biliar do laurilsulfato de tetraciclina. Obtiveram concentração biliar superior a das outras tetraciclinas, conseguindo melhora em 65,3\% dos doentes. Em 2 pacientes verificaram pirose passageira.

Visando comprovar a utilidade do laurilsulfato de tetraciclina, usamos o medicamento em doentes hospitalizados ou não.

\section{MATERIAL E METTODOS}

Foram analisados neste estudo pacientes hospitalizados nos Serviço de Doenças Tropicais e Infecciosas da. Faculdade de Medicina de P. Alegre, U.F.R.G.S., do Serviço de Doenças Infecciosas e Parasitárias da Faculdade Católica de Medicina de P. Alegre e de ambulatório.

Como plano de trabalho, convencionou-se submeter os doentes a serem tratados com lauraciclina a exame clínico completo, exames bacteriológicos para esclarecimento da etiologia da doença, exame comum de urina, provas funcionais hepáticas, dosagem das transaminases, hemograma, pelo menos no início e ao fim do tratamento, além dos exames de rotina e necessários a cada caso em particular, como radiografias do pulmão, exames especializados, etc. Sempre que exeqüível seria realizado o antibiograma.

Como, freqüentemente, acontece em nosso meio, alguns pacientes de ambulatório e, mesmo, alguns hospitalizados não realizaram tôdas as provas previstas por motivos alheios à nossa vontade.

Dos 19 pacientes tratados, 10 eram do sexo masculino e 9 do sexo feminino. Dêles, 3 tinham menos de 5 anos, 3 entre 10 e 19 anos, 4 entre 20 e 29,5 entre 30 e 39,1 entre 40 e 49, 1 entre 50 e 59,1 entre 60 e 69 e 1 entre 70 e 79 anos.
A presença de casos não habitualmente internados em Serviços de Doenças Infecciosas e Parasitárias é fácil de explicar. Alguns doentes após consultarem, foram, por motivos óbvios, submetidos a tratamento ambulatório. Em outros, enviados pela triagem hospitalar, por serem portadores de processos febris ainda não esclarecidos, os exames posteriores chegaram a outros diagnósticos que não os de âmbito específico dos Serviços.

Os doentes foram tratados com doses variáveis de laurilsulfato de tetraciclina de acôrda com suas idades e gravidade do caso. Por princípio, nunca usamos menos de $100 \mathrm{mg}$ por dose, mesmo em crianças pequenas.

Também demos preferência a injeçōes intramusculares repetidas de 12 em 12 horas até a normalização da temperatura, salvo em 2 casos que reputamos, de início, de pouca gravidade, quando as fizemos de 24 em 24 horas.

Consideramos a droga inoperante quando de 8 a 10 dias, a sintomatologia não cedeu ou, mesmo, se agravou, e classificamos então o resultado de nulo.

No paciente em que houve melhora com negativação bacteriológica temporária e depois reaparição gradativa dos fenômenos mórbidos, consideramos o êxito como parcial.

No doente em que as manifestações clínicas regrediram, mas lentamente, com algumas alternativas de agravação e melhora, consideramos o resultado bom.

Rotulamos de excelente os casos em que houve redução progressiva dos sintomas até a cura clínica e a laboratorial, quando possível e a nosso alcance.

\section{ANÁLISE DOS RESULTADGS COMENTÁRIOS}

Em nosso grupo (Tabela 1), avultaram as anginas e as pneumopatias (13 casos em 19).

Tôdas as infecções agudas dêstes tipos obtiveram excelente resultado.

o paciente 4 , com bronquectasias infectadas, de 69 anos de idade, inclusive já submetido a toracoplastia, obteve a regressão de seus sintomas no 5.o dia de tratamento. Mais tarde, após à suspensão da terapêutica, no 17.0 dia dọ início do tra- 
TABELA 1 - DOSES E RESULTADOS OBTIDOS COM LAURILSULFATO DE TETRACICLINA EM DIVERSAS INFECÇŐES

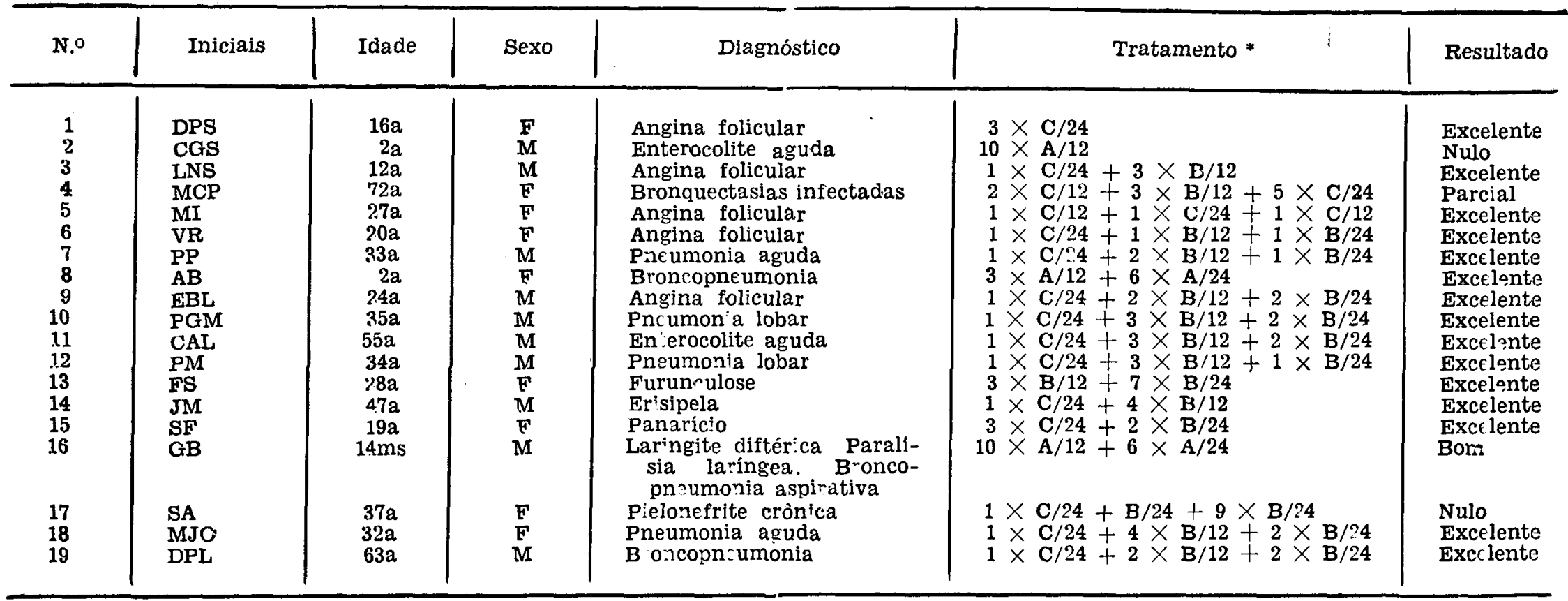

- A cifra que precede o sinal $X$ ind ca o número do dias em que foi fmpregada a dose.

A Corresponde à injeção de $100 \mathrm{mg}$, B a de $250 \mathrm{mg}$ e C a de $500 \mathrm{mg}$ de launilsulfato de tetraciclina.

O denominador da frarão corresnonde ao intervalo em hor ens entre as inieçôes.

Exemplos: $1 \times$ C/24 significa uma injeção de $500 \mathrm{mg}$ nas 24 horas, durante um dia.

$2 \times \mathrm{B} / 12$ é o símbolo para do's dias de injeções de $250 \mathrm{mg}$ de 12 ou 16 horas. 
TABELA 2 - AGENTE ETIOLOGICO DE DIVERSAS INFECÇOES TRATADAS COM LAURILSULFATO DE TETRACICLINA

\begin{tabular}{|c|c|c|c|c|c|c|}
\hline Paciente & Iniciais & Idade & Sexo & Diagnóstico & Agente et:ológico & Resultados \\
\hline 1 & DPS & $16 a$ & $\mathbf{F}$ & Angina folicular & $\begin{array}{l}\text { Streptoccus beta hemolyticus. Associa- } \\
\text { çáo fuso-espirilar. }\end{array}$ & Excelente \\
\hline 2 & CGS & $2 a$ & $\mathbf{M}$ & Enterocolite aguda & $\begin{array}{l}\text { Escherichia coli 0111-B4. Klebsiella Ae- } \\
\text { robacter. }\end{array}$ & Nulo \\
\hline 4 & MCP & $72 a$ & $\mathbf{M}$ & Bronquectasias infectadas & $\begin{array}{l}\text { Streptoccus beta hemolyticus. Diplo- } \\
\text { coccus pneumoniae. Klebsiella-Aero- } \\
\text { pacter. }\end{array}$ & Parcial \\
\hline 5 & MI & $27 a$ & $\mathbf{F}$ & Angina folicular & Streptoccocus beta hemolyticus & Excelente \\
\hline 8 & $\mathbf{A B}$ & $2 a$ & $\mathbf{F}$ & Broncopneumonia & Streptoccocus beta hemolyticus & Excelente \\
\hline 10 & PGM & $35 \mathrm{a}$ & $\mathbf{M}$ & Pneumonia & Diplococcus pneumoniae. & Excelente \\
\hline 11 & CAL & $55 a$ & $\mathbf{M}$ & Enterocolite aguda & Zlebsiella-Aerobacter. & Excelente \\
\hline 12 & $\mathbf{R M}$ & $34 a$ & $\mathbf{M}$ & Pneumonia lobar & Diplococcus pneumoniae. & Excelente \\
\hline 17 & SA & $37 a$ & $F$ & Pielonefrite crônica & Escherichia coli & Nulo \\
\hline 18 & MJO & $32 a$ & $\mathbf{F}$ & Pneumopatía aguda & Streptoroccus beta hemolyticus & Excelente \\
\hline 19 & DPL & $63 a$ & $\mathbf{M}$ & Broncopneumonia & Streptococcus beta hemolyticus & Excelente \\
\hline
\end{tabular}


tamento, reapareceu a febre e aumentou a expectoração. Classificamos o resultado apenas de parcial. Entre os seis pacientes restantes, houve 2 infecções entéricas agudas. Uma, caso 2, com cultura positiva de Klebsiella - Aerobacter e E'scherichia coli patogênica, 0111-B4 nas fezes, não se beneficiou com o tratamento pela lauraciclina. A outra também determinada por Klebsiella-Aerobacter teve rápida regressão.

Não conseguimos também resultados terapêuticos com o caso 17 . A doente, portadora de pielonefrite crônica, já fizera tratamentos repetidos com diversos antibióticos, obtendo sempre pourco sucesso. O germe responsável obtido em urocultura foi a Escherichia coli.

Os 3 doentes, um com furunculose, outro com erisipela e o último, com panarício em evolução, obtiveram a regressão rápida de seus sintomas e o resultado pode ser considerado excelente.

Conseguimos identificar o agente patogênico em 11 de 19 pacientes (Tabela 2).

Em três casos 5,8 e 18 , nos quais o germe responsável foi o estreptococo beta-hemolitico, em dois, casos 1 e 19, em que, além dêle, foram encontrados associação fusoespirilar e hemófilo, respectivamente e em outros dois, casos 10 e 12, cujo agente identificado foi o pneumococo, o resultado terapêtico foi excelente.

Em compensação, nos casos 2 e 7, determinados pelo colibacilo no primeiro juntamente com bactérias de tipo KlebsiellaAerobacter e no segundo, isoladamente, o resultado foi nulo.
$\mathrm{Em}$ um doente, caso 4, em que foram isolados estreptococos, pneumonococos e bacilo de Friedländer, a ação do medicamento foi considerada parcial.

Finalmente, no caso 11 , onde foi cultivada Klebsiella-Aerobacter o sucesso foi total.

o medicamento não determinou, pràticamente, fenômenos de intolerância local quando realizado em injeções intramusculares profundas. Sòmente a paciente 5 apresentou tumor que desapareceu gradativa e espontâneamente em poucos dias.

Três doentes se queixaram de dor tardia, passageira, após as injeções.

Uma das pacientes, a de número 13 , teve urticária no quarto dia do tratamento. O uso de drogas anti-histaminicas determinou a rápida regressão dos sintomas.

Não observamos outras manifestações clinicas imputáveis à droga.

Em oito pacientes em que realizamos provas funcionais hepáticas e/ou dosagem das transaminases e, em sete, nos quais realizamos hemogramas de verificação, não constatamos alteraçōes significativas atribuiveis à ação nociva do medicamento.

Em sintese, podemos dizer que os resultados obtidos com o laurilsulfato de tetraciclina foram muito bons.

Em 19 casos, obtivemos 15 sucessos, rotulados de excelente $(\mathbf{7 8 , 9} \%$ ), além de outro catalogado de bom, que eleva a porcentagem de resultados satisfatónios para $84,2 \%$.

The authors give general considerations about the employment of tetracycline compounds in infectious diseases.

They describe their experience in the application of tetracycline laurilsulfate in intramuscular injections.

They dealt with 19 different kinds of infections with this drug: 5 acute pharyngitis, 8 pulmonary infections, 2 acute enteritis, 1 furunculosis, 1 pyelonephritis, 1 erysipelas, and 1 panaris. They got 15 excellent, and one good results $(84,2 \%)$. urticaria.

Collateral phenomenons were not observed by them, excepting one case of 


\section{BIBLIOGRAFIA}

: - ALARCOS LLORACH, A.. HILANDERAS SANCHEZ, J., PÉREZ HERREZUELC, F. \& GONZÁLEZ GONZÁLEZ, M.: Experiencias clínicas con laurilsulfato de tetraciclina (Lauraciclina). Separata do Münch. Med. Woch., ed. esp., n. ${ }^{12}, 832-840,1966$.

2 - BOOTHE, J.H., MORTON, J., II, PETISI, J. P., WILKINSON, R. G. \& WILLIAMS, J.H.: Tetracycline. J. Am. Chem. Soc. 75: 4621, 1963.

3 - CAMPOMANES GALLEGO, E., SALLENT, J.A., PÉREZ MOTA. A., \& IZQUIERDO, M.:. Investigación clínica sobre eliminación biliar del laurilsulfato de tetraciclina ( $\mathrm{LH}-90)$. Separata do Med. Klin., ed. esp., n. ${ }^{\circ}$ 67, 76-81, 1967.

4 - DUGGAR, B.M.: Aureomycin. A product of the continuing search for new antibiotics. Ann. New York Acad. Sc. 51: 177-181, 1948.

5 -. FABRE, J.: Distribution and excretion of doxycycline in normal man. Chemotherapia 11: 7385, 1966.
6 -- FOZ M., REY, C. \& IZQUIERDO. M.: Estudio clínjco y de concentraciones hemáticas del laurilsulfato de tetraciclina. Münch. Med. Woch, ed. esp., n.) 11: 754-761, 1966.

7 - GONZÁLEZ Y GONZÁLEZ, J.A. \& RUBIO CLEMENTE, F.: Ensayo clinico com laurilsulfato de tetraciclina en infecciones urinarias y del aparato respiratorio. Separata do Med. Klin., ed. esp., n.o $69,88-96,1967$

8 -- IZQUIERDO, M., FELIU, L., JURADO, A. \& FOLCH, C.: Un nouveau derivé de la tetracycline à absorption prolongée. Chimie Thérap. n. 5-6: 314-319, 1966.

9 - IZQUIERDO, M. \& GOÑALONS, E.: Niveles hemáticos acumulativos por administración parenteral de un nuevo derivado de teraciclina. 7.0 Congr. Inter. Soc. Farm. Mediterraneo Latino. Bordéus, 16 a 18 de maio de 1966. 


\section{SOCIEDADE BRASILEIRA DE HIGIENE}

Fol eleita, por unanimidade, na Assembléia Geral da Sociedade Brasileira de Higiene, reunida sob a presidência do prof. Manoel José Ferreira, a nova Diretoria para o periodo 1968-1969. São os seguintes os membros da atual Diretoria: Presidente Dr. Nilson Guimarães; Vice-Presidente Dr. Ataúlfo Coutinho; Secretário-Executivo - Dr. Armando Lages; Secretário Dr. Dagoberto Chaves; Tesoureiro - Dr. Hamilton Abreui Bibliotecário - Dr. Walter Silva, além de un co.ısulno consultivo, uma comissão de redação e uma comissão fiscal.

O nôvo Presidente eleito é personalidade das mais destacadas no sanitarismo nacio- nal, desempenhando, entre outras, as funções de Assistente Técnico do Departamento Nacional de Endernias Rurais, Vice-Presidente da Federação Internacional de Higiene e Medicina Preventiva e comendador da Ordem Nacional do Mérito Médico.

\section{SEGUNDO CONGRESSO MUNDIAL DA SOCIEDADE INTERNACIONAL DE DË_LVATOLOGIA TROPICAL}

Realizar-se-á em Kioto, no Japão, de 15 a 20 de agôsto. Maiores detalhes com o Prof. Kasuke Ito, Diretor. Departamento de Dermalo ozja Un:versidade Nacional de Gifu, Cidade de Gifu, Japão. 